\section{Encefalitis autoinmunes: criterios diagnósticos y pautas terapéuticas}

\author{
JUAN PABLO COLLAO PARRA ${ }^{1}$, CÉSAR ROMERO URRA ${ }^{1, a}$, \\ CAROLINA DELGADO DERIO ${ }^{1,2,3}$
}

\section{Autoimmune encephalitis. A review}

Autoimmune encephalitis are one of the emergent causes of subacute changes in the level of consciousness, behavior, cognitive impairment and seizures, mainly in young people. They are a consequence of inflammation or dysfunction of parts of the brain caused by antibodies against specific brain antigens, usually located in the limbic system, resulting in clinical presentation as a limbic encephalitis. The objectives of this article are to show the clinical presentation, complementary studies and treatment of this entity, considering that the patient's prognostic depends on a high level of clinical suspicion, and on an early initiation of immunosuppressive therapy. We did a nonsystematic review of the literature on autoimmune encephalitis between 2005 and 2017. We conclude that the prevalence of autoimmune encephalitis is increasing, even surpassing infectious causes of encephalitis in developed countries. Clinical presentation includes sub-acute cognitive and behavioral impairment, with or without alterations in consciousness and seizures. Fever and inflammation of the cerebrospinal fluid are less common than in the infectious causes but psychiatric symptoms are more frequent. There are specific clinical presentations according to the particular type of antigen/antibody present, which also determines the association with cancer, constituting a paraneoplastic syndrome only in some cases. Immunosuppressive therapy has been standardized in steps, and should be initiated early to improve prognosis.

(Rev Med Chile 2018; 146: 351-361)

Key words: Autoimmunity; Encephalitis; Receptors, N-MethylD-Aspartate.
'Departamento de Neurología y Neurocirugía. Hospital Clínico Universidad de Chile. Santiago, Chile.

${ }^{2}$ Departamento de Neurología y Neurocirugía. Clínica Santa

María. Santiago, Chile.

${ }^{3}$ Departamento de Neurociencias. Universidad de Chile. Santiago,

Chile.

aLicenciado en medicina, estudiante de $7^{\circ}$ año de Medicina, Universidad de Chile.

Durante la realización de este trabajo Carolina Delgado recibió financiamiento del proyecto anillo ACT1403 PIA CONICYT Ninguno de los autores tiene otro conflicto de interés.

Recibido el 27 de mayo de 2017 , aceptado el 28 de diciembre de 2017.

Correspondencia a: Carolina Delgado Derio Departamento de Neurología y Neurocirugía. Hospital Clínico Universidad de Chile.

Santos Dumont 999, Independencia, Santiago, Chile. carodede@gmail.com

\section{L} a encefalitis corresponde a una inflamación del tejido cerebral asociada a disfunción neurológica; si además del cerebro se inflaman las meninges se habla de meningo encefalitis, y se habla de encefalopatía si hay disfunción del parénquima cerebral pero sin inflamación ${ }^{1}$. Este cuadro tiene distintas causas y formas de presentación, pudiendo afectar a personas de diversa edad, género y raza. Es una causa importante de secuelas neurológicas, especialmente en personas jóvenes ${ }^{1,2}$.

Las causas de encefalitis se pueden dividir en aquellas de origen infeccioso, post infeccioso, paraneoplásico y autoinmune, pero aproximadamente $60 \%$ de los casos quedan sin diagnóstico preciso $^{3}$.
Las encefalitis o encefalopatías autoinmunes son las causadas por factores inmunológicos como anticuerpos o bien inmunidad celular contra antígenos presentes parénquima cerebral ${ }^{4}$. Según cuál sea el tipo de inmunidad y antígeno en cuestión, se pueden subdividir las encefalitis autoinmunes en las producidas por anticuerpos (AC) contra antígenos superficie celular y las contra antígenos intracitoplasmáticos. En las primeras, los AC tienen un rol patogénico por sí mismos, produciendo alteración funcional de los receptores $(\mathrm{R}) \mathrm{u}$ otras proteínas de membrana, como es el caso de la encefalitis por AC anti receptor de N-metil-D aspartato (R-NMDA); estos subtipos de encefalitis tienen una asociación variable a neoplasias sisté- 
micas $^{5}$. En las contra antígenos intracitoplasmáticos el daño está relacionado con la inmunidad celular y tienen una fuerte asociación a tumores, como es el caso de los AC anti núcleo neuronal tipo 1 y tipo 2 (ANNA-1 y 2) o anti Hu y anti Ri respectivamente ${ }^{5}$. También las hay producidas por inmunidad contra antígenos no esclarecidos (aún) como la encefalomielitis (con asociación variable con $\mathrm{AC}$ anti $\mathrm{MOG}$ ), la encefalitis lúpica y la encefalitis de Hashimoto ${ }^{4,5}$.

La prevalencia exacta de las encefalitis autoinmunes es incierta, existiendo un aumento importante del reporte de casos en los últimos 10 años, asociado al avance en la pesquisa de los anticuerpos contra un antígeno celular específico ${ }^{6}$. Desde que se descubrieron los AC anti R-NMDA en el $2005^{7}$, la prevalencia de la encefalitis por AC anti R-NMDA ha aumentado de manera exponencial; así en un estudio de las causas de encefalitis a todas las edades realizado de $2004-2006^{2}$, las encefalitis autoinmunes constituyeron $21 \%$ del total, siendo la encefalomielitis aguda diseminada la causa autoinmune más frecuente, seguida por la por AC anti R-NMDA, siendo las causas infecciosas $42 \%$ del total, con la encefalitis por el virus Herpes Simplex tipo 1 (VHS-1) en el primer lugar (19\%) ${ }^{2}$. En una cohorte entre el 2007-2011 del "Proyecto de encefalitis de California", la encefalitis por AC anti R-NMDA fue la primera causa de encefalitis ( $41 \%$ del total), superando inclusive a las causas virales individuales en los menores de 30 años $(38 \% \text { enterovirus, } 9 \% \text { VHS- } 1)^{8}$, estimándose que la encefalitis por AC anti R-NMDA representa al menos $1 \%$ de los pacientes jóvenes en cuidados intensivos ${ }^{6}$.

En el año 2013, el Consorcio Internacional de encefalitis, publicó algoritmos diagnósticos, para uniformar el estudio básico inicial y ajustar la sospecha clínica ${ }^{1}$ (Tabla 1A). Si bien estos algoritmos diagnósticos son útiles para el estudio de las encefalitis de causa infecciosa, no lo son tanto para aquellas de etiología autoinmune, las cuales pueden tener un inicio más insidioso, poca fiebre y menor inflamación del líquido cefalo raquídeo (LCR), y presentan más frecuentemente síntomas psiquiátricos, crisis epilépticas e inestabilidad autonómica $^{3,8,9}$. Debido a estas diferencias y a la creciente cantidad de nuevos casos, Graus y colaboradores en el $2016^{4}$ publicaron una estandarización del estudio y diagnóstico de la encefalitis autoinmune. En estos criterios se dio énfasis a la presentación clínica y hallazgos en el estudio complementario, tratando de obviar la necesidad de contar con los anticuerpos específicos, debido a lo poco disponible de éstos en la mayoría de los países. Dentro de esta estandarización, hay algunos criterios muy sensibles, pero poco específicos como los de "encefalitis autoinmune posible” (Tabla 1B), categoría en la que pueden coincidir fácilmente cuadros de origen primariamente psiquiátrico, lo cual limita su validez, pero da énfasis al inicio precoz del tratamiento inmunosupresor una vez descartadas las causas infecciosas y metabólicas ${ }^{4}$. También hay criterios más específicos como los de "encefalitis límbica definitiva" (Tabla 1C) y los de encefalitis por AC anti R-NMDA probable (Tabla 2), las que por su presentación clínica característica ameritaban contar con criterios aparte ${ }^{4}$.

\section{Métodos}

Hicimos una revisión en Pubmed con los términos "autoimmune encephalitis" y scielo con "encefalitis autoinmune", seleccionamos aquellos artículos que tuviesen el mayor número de pacientes descritos y aquellos publicados en Chile. Además incluimos artículos de revisión "de expertos” y criterios diagnósticos de las sociedades de encefalitis internacionales. Finalmente hicimos un resumen solo de los cuadros clínicos que se manifiestan principalmente con "alteración del estado mental y/o alteración cognitiva y/o cambios en la conducta", excluyendo a trastornos que se presentan con síntomas de compromiso motor y sensitivo primariamente ${ }^{4,5}$.

\section{Presentación clínica}

Las características clínicas de las encefalopatías autoinmunes varían según cuál sea el tipo de anticuerpo anti neuronal involucrado (Tabla $3)^{4,5,10-18}$, pero en general tienden a tener un perfil temporal de presentación subaguda, alcanzando su peak en semanas a meses desde el inicio de los síntomas. También puede haber un pródromo con cefalea y fiebre, pero de menor cuantía respecto a las encefalitis infecciosas ${ }^{4}$.

Habitualmente se presentan con alteraciones conductuales y cognitivas y/o crisis epilépticas ${ }^{3}$, siendo diagnóstico diferencial de cuadros de psicosis confusas ${ }^{19}$, demencias rápidamente pro- 
Tabla 1. Criterios diagnósticos de encefalitis. A: General ${ }^{1}$. B: Autoinmune ${ }^{4}$, C: $^{2}$ Límbica $^{4}$

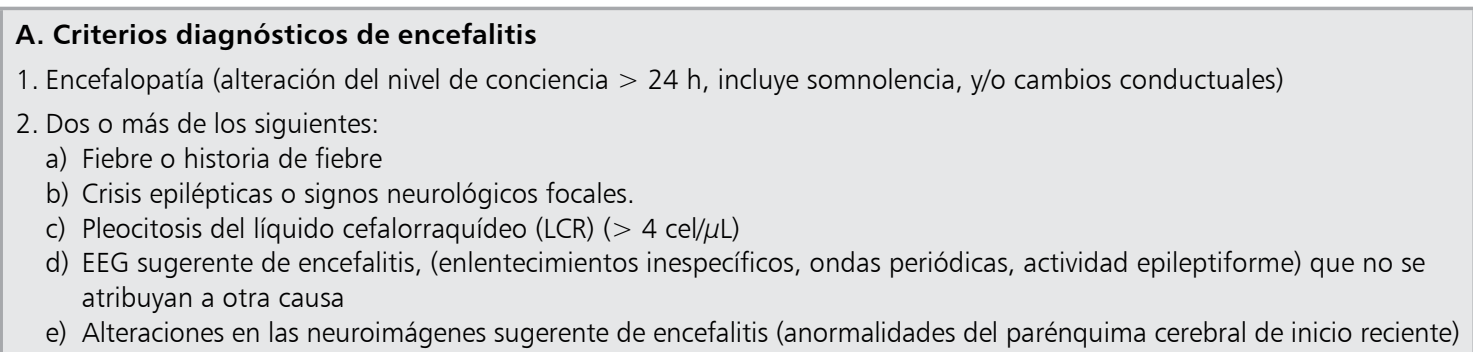

\section{B. Criterios diagnósticos para encefalitis autoinmune (posible)}

Debe cumplir los 3 criterios

1. Perfil subagudo $<3$ meses de evolución:

Déficit en la memoria de trabajo, alteración del estado mental o síntomas psiquiátricos

2. Al menos uno de los siguientes:

a) Nuevos hallazgos focales del SNC

b) Crisis epilépticas no explicadas por epilepsia antigua

c) Pleiocitosis del LCR $>4 \mathrm{cel} / \mu \mathrm{L}$.

d) RM de cerebro sugerente de encefalitis (hiperintensidad en T2 o flair de lóbulo temporal medial, compromiso multifocal de sustancia gris, blanca o ambas compatible con desmielinización o inflamación) (Figura 1)

3. Exclusión de otras causas

\section{Criterios diagnósticos para encefalitis límbica definitiva}

Debe cumplir los 4 criterios (pueden ser 3 más la presencia de anticuerpos antineuronales o anti onconeurales)

1. Perfil subagudo $<3$ meses de evolución:

Déficit en la memoria de trabajo y corto plazo, síntomas psiquiátricos, crisis epilépticas

2. RM de cerebro con hiperintensidad en T2 o Flair restringido al lóbulo temporal medial bilateral

3. Al menos uno de los siguientes:

a. Pleiocitosis del LCR $>4 \mathrm{cel} / \mu \mathrm{L}$

b. EEG con actividad lenta o epiléptica en los lóbulos temporales

4. Exclusión de otras causas

*LCR: Líquido cefalorraquídeo; RM: Resonancia magnética; EEG: Electroencefalograma.

gresivas $^{9,20}$ y epilepsias refractarias de reciente inicio $^{21,22}$. Dentro de las alteraciones de la conducta son frecuentes los síntomas de ansiedad, cambios de ánimo y síntomas psicóticos como alucinaciones e ideas delirantes; éstas habitualmente no son bien sistematizadas ${ }^{20}$. Dentro de las alteraciones cognitivas suele haber focalidad, que varía según cuáles sean las áreas del cerebro afectadas, predominando la amnesia anterógrada, inatención, y disfunción ejecutiva ${ }^{4}$. Las crisis convulsivas suelen ser de inicio focal secundariamente generalizadas. Cuando hay síntomas y signos de afección del sistema límbico como hipocampos (amnesia y crisis convulsivas), complejo amigdalino y/o corteza orbito frontal (síntomas conductuales), sindromáticamente corresponde a una "encefalitis límbica” pero para aumentar la especificidad los nuevos criterios relegan este nombre a cuadros en que se objetivan las alteraciones de estas estructuras en las neuroimágenes (Tabla $1 \mathrm{C}$, Figura $1 \mathrm{~A}$, B, Tabla 3$)^{4,5,10-18}$.

\section{Estudio y manejo}

Dentro del estudio de las encefalopatías como primera medida hay que descartar causas infecciosas, vasculares y metabólicas. Se debe realizar una resonancia magnética (RM) de cerebro con contraste, un análisis del LCR con la medición de las células, proteínas, glucorraquia y búsqueda de los agentes infecciosos más frecuentes, y la medición de bandas oligoclonales para determinar presencia de anticuerpos en el LCR ${ }^{2}$. Además 
Tabla 2. Criterios diagnósticos para encefalitis por anticuerpos anti R-NMDA ${ }^{4}$

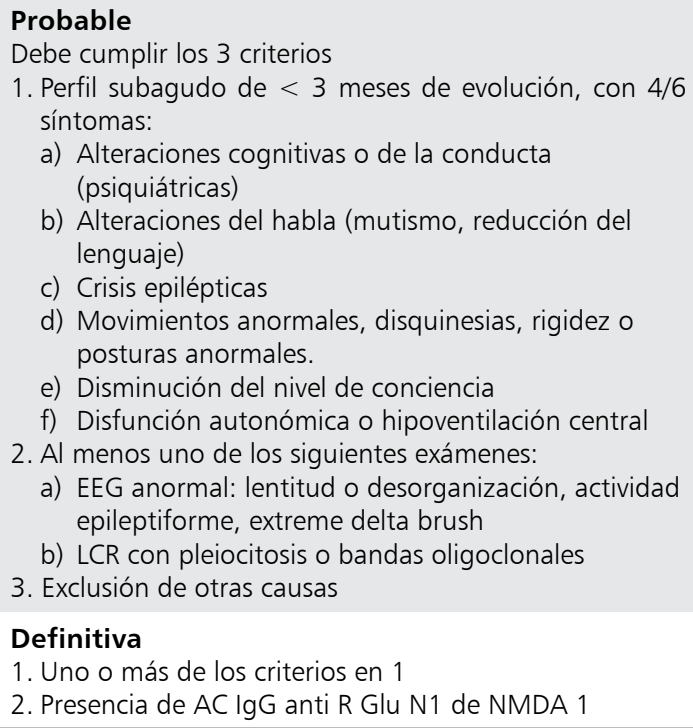

1. Perfil subagudo de $<3$ meses de evolución, con $4 / 6$ síntomas:

a) Alteraciones cognitivas o de la conducta (psiquiátricas)

b) Alteraciones del habla (mutismo, reducción del lenguaje)

c) Crisis epilépticas

d) Movimientos anormales, disquinesias, rigidez o posturas anormales.

e) Disminución del nivel de conciencia

f) Disfunción autonómica o hipoventilación central

2. Al menos uno de los siguientes exámenes:

a) EEG anormal: lentitud o desorganización, actividad epileptiforme, extreme delta brush

b) LCR con pleiocitosis o bandas oligoclonales

3. Exclusión de otras causas

\section{Definitiva}

1. Uno o más de los criterios en 1

2. Presencia de AC IgG anti R Glu N1 de NMDA 1

*LCR: Líquido cefalorraquídeo; EEG: Electroencefalograma. debe realizarse un electroencefalograma estándar, o idealmente una monitorización continua en el caso de compromiso de conciencia. El esquema y requerimientos para el estudio de la encefalitis/encefalopatía en adultos se desglosa en la Tabla $4^{1,4,17}$.

\section{Búsqueda de los anticuerpos anti neuronales específicos}

La ventaja de su identificación es que dan "certeza diagnóstica” si son positivos y están asociados a un cuadro clínico compatible. Su disponibilidad evitaría la búsqueda de agentes infecciosos infrecuentes, cuando el estudio de las causas infecciosas más frecuentes en cada país resulta negativo ${ }^{3}$. Favorece estructurar el estudio de neoplasia oculta, ya que hay anticuerpos fuertemente asociados a un tipo de cáncer determinado y otros casi nunca asociados a cáncer como aquellos dirigidos contra LGI-1 o los anti GAD65 $5^{23}$ (Tabla 3). Además su positividad permite iniciar un tratamiento más específico de manera oportuna, con lo cual mejora el pronóstico a largo plazo ${ }^{11}$.

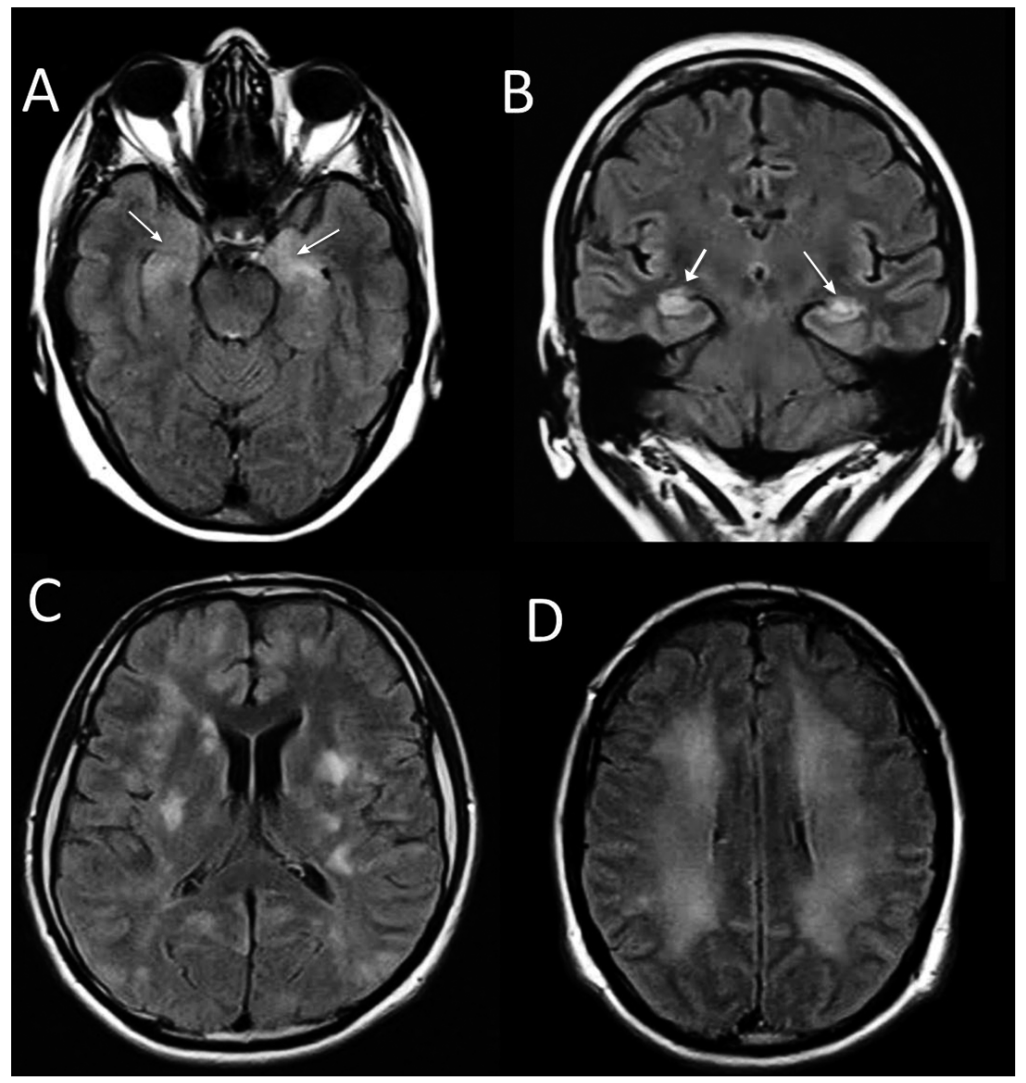

Figura 1. Resonancia magnética cerebral secuencia FLAIR de pacientes evaluados por los autores que cumplen con los criterios de encefalitis autoinmune: A y B. Hiperintensidad en ambos lóbulos temporales mediales característicos de una encefalitis límbi$c a$, en paciente mujer de 50 años que reúne estos criterios. C. Múltiples focos hiperintensos cortico-subcorticales reversibles con tratamiento inmunosupresor en paciente varón de 45 años. D. Hiperintensidad homogénea de la sustancia blanca profunda reversible al tratamiento inmunosupresor en varón de 65 años. 


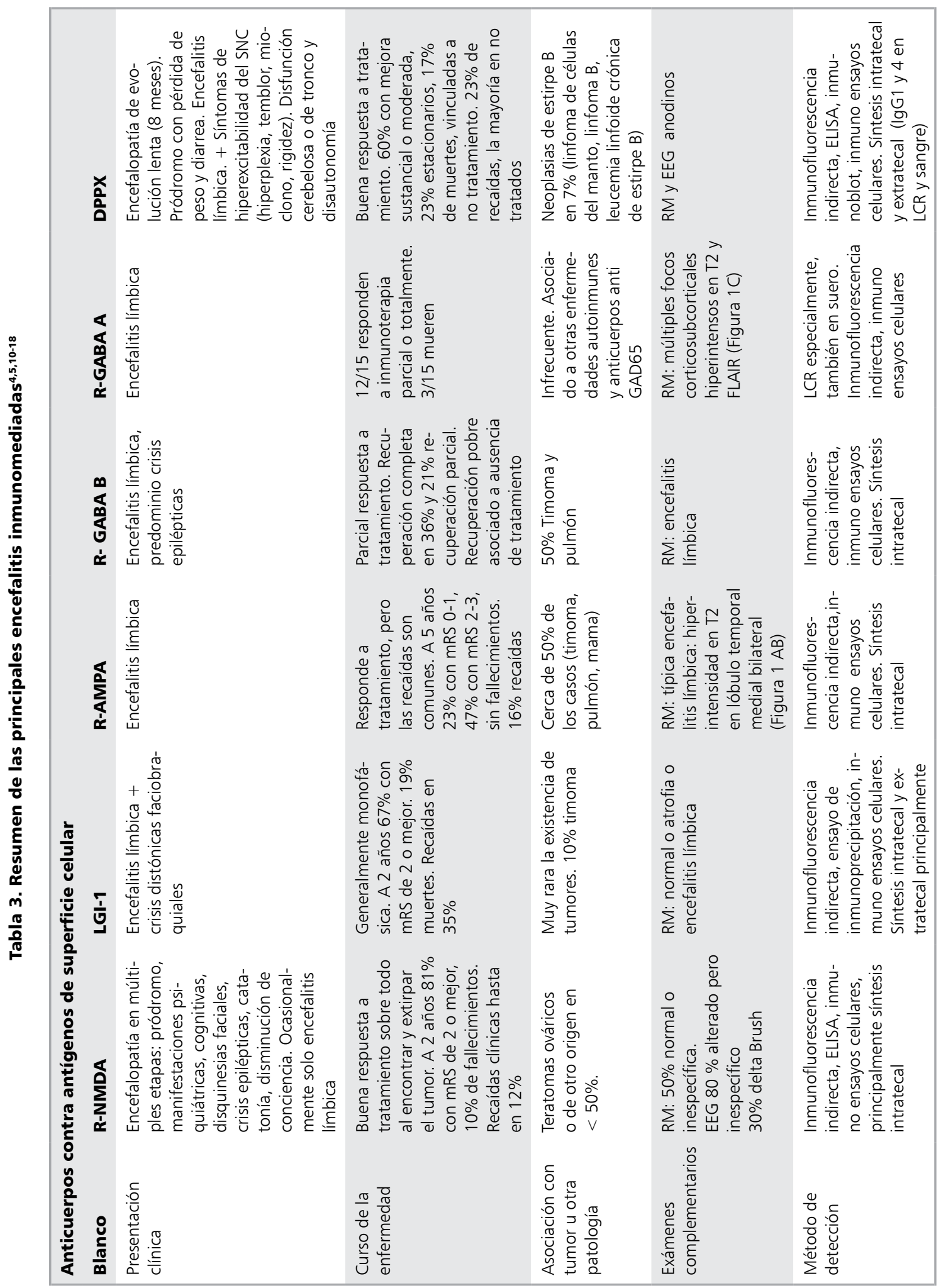




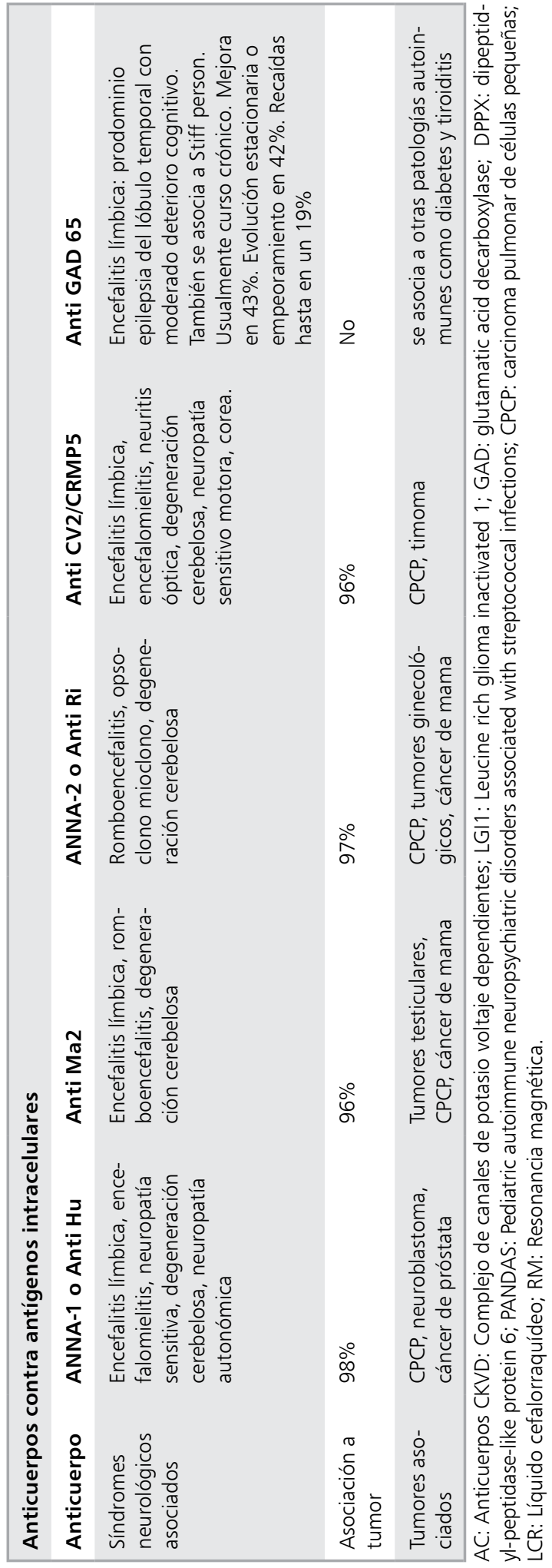

Se recomienda fuertemente la medición de éstos AC en LCR y plasma, ya que la medición solo en plasma se asocia tanto a falsos positivos como a falsos negativos ${ }^{24}$. Así, en el caso de los AC anti R-NMDA, se ha encontrado una prevalencia de $\mathrm{AC}$ positivos en plasma (IgG,o IgM, o IgA) en $4-7 \%$ de la población general, pero con títulos bajos, los cuales son negativos en el estudio de $\mathrm{LCR}^{24}$. Por otro lado, los AC anti R-NMDA en el LCR tienen mucho mejor correlación con el estado clínico que los AC en el plasma ${ }^{25}$. No así en los AC anti LGi-1 que son frecuentemente positivos sólo en suero (Tabla 3 ).

Actualmente en Chile es posible hacer el análisis deLCR en el laboratorio de la red salud Universidad Católica.

\section{Diagnóstico diferencial}

Está en relación a las otras encefalopatías agudas o subagudas asociadas a síntomas neuropsiquiátricos y crisis convulsivas (síndrome de encefalitis límbica) y/o movimientos anormales. Entre ellas destacan las encefalitis infecciosas sobre todo la producida por VHS-1, que si bien es la más frecuente, clínicamente tiene una presentación más aguda, con más fiebre, mayor pleocitocis del LCR. La por virus Herpes tipo 6 da una encefalitis límbica típica, se presenta más frecuentemente (pero no exclusivamente) en inmunocomprometidos ${ }^{3}$. También son importantes diagnósticos diferenciales por su presentación subaguda la sífilis, tuberculosis, borreliosis, y la infección por $\mathrm{VIH}^{1}$. Dentro de las causas autoinmunes la vasculitis primaria del sistema nervioso central, sobre todo la de vaso pequeño, es un diagnóstico diferencial muy difícil, ya que se presenta de manera subaguda con cefalea y encefalopatía progresiva, con neuroimágenes muy inespecíficas, siendo necesario muchas veces llegar a la biopsia cerebral $^{26}$. Otros desórdenes desmielinizantes distintos al ADEM como neuromielitis óptica o esclerosis múltiple suelen tener una presentación sin encefalopatía ${ }^{4,9,27}$. Dentro de los tumores del SNC, pueden tener una clínica parecida los linfomas primarios del SNC y la gliomatosis de lóbulo temporal, pero suelen tener diferencias en las neuroimágenes el primero y en la respuesta a tratamiento el segundo ${ }^{9,27}$.

Dentro de las causas de demencia rápida- 
Tabla 4. Esquema de estudio de las encefalitis $(1,4,17)$

\section{LCR}

Recolectar al menos 20 cc de fluido si es posible; congelar al menos 5-10 cc Medir: presión de apertura, proteínas, glucosa, recuento de hematíes, recuento de leucocitos

Tinción de gram y cultivo corriente

PCR para VHS 1 y 2 (Considerar IgG e IgM para VHS en LCR)

PCR para VVZ (Considerar IgG e IgM para VVZ en LCR)

PCR para enterovirus

VDRL

Látex para Cryptococcus y/o tinción con tinta china

Bandas oligoclonales y recuento de IgG

\section{Suero}

Estudios sanguíneo metabólicos

Elisa para VIH (Considerar PCR)

Pruebas treponémicas específicas

Mantener suero en la situación aguda y volver a extraer suero 10-14 días después para test de anticuerpos pareados

Estudio de autoinmunidad: ANA, ENA, anti DNA doble cadena, Complemento C3 y C4, ANCA, estudio de síndrome antifosfolípidos, anticuerpos antitiroideos y antitiroglobulina

\section{Imágenes}

RM cerebral que incluya técnica de difusión y contraste

\section{Neurofisiología}

EEG estándar o monitorización continua

\section{Otros tejidos/fluidos}

Si existen manifestaciones fuera del SNC, se recomienda realizar estudio adicional (Por ejemplo, de lesiones cutáneas, lavado bronquealveolar, estudio de desposiciones)

\section{Según factores del huésped}

En inmunocomprometidos, búsqueda de infecciones oportunistas: PCR para CMV, HHV 6 y 7 y HIV (en LCR), Serología para Toxoplasma gondii y/o PCR, Test para TBC, Test para hongos

\section{Búsqueda de neoplasia oculta}

TC de tórax, abdomen y pelvis con contraste. Considerar realizar PET/PET TC. (En búsqueda de carcinomas pulmonares especialmente de células pequeñas, timomas, tumores ováricos, tumores testiculares, linfoma de Hodgkin, entre otros) Mamografía (screening), seguido de RM mamaria si se encuentra alterada Ecografía transvaginal (en búsqueda de teratomas y carcinomas ováricos)

Ecografía testicular. La biopsia se recomienda en hombres menores a 50 años con microcalcificaciones al ultrasonido Estudio de marcadores tumorales en suero (CA 19-9, CA 125, CEA, AFP, Beta hCG)

\section{Estudio de anticuerpos anti antígenos intracitoplasmáticos en suero}

Anti Hu, Anti Ma 2, Anti Ri , anti GAD 65 (Disponibles en clínicas de Santiago). Si el paciente tiene serología positiva para alguno de estos anticuerpos, clínica compatible con un síndrome paraneoplásico y los estudios en búsqueda de neoplasia resultan negativos, el screening previo debe repetirse en 3 a 6 meses, seguido de screening regular cada 6 meses por 4 años

\section{Estudio de anticuerpos anti antígenos de superficie en LCR y /o suero}

Anti R-NMDA, anti GABA $B^{\prime}$ anti GABA $A_{A}$ Anti R AMPA, Anti LGI 1*

LCR: Líquido cefalorraquídeo; PCR: polymerase chain reaction, reacción en cadena de la polimerasa; VHS: Virus herpes simple; VVZ: Virus Varicela Zóster; VIH: Virus de la inmunodeficiencia humana; ANA: anticuerpos antinucleares; ENA: anticuerpos anti antígenos extratables; ANCA: anticuerpos anti citoplasma de neutrófilos; RM: resonancia magnética; EEG: electroencefalograma; CMV: citomegalovirus; HHV: herpes virus humano; TBC: tuberculosis; TC: tomografía computada; PET: tomografía de emisión de positrones; CEA: antígeno carcinoembrionario; AFP: alfafetoproteína. *Se pueden solicitar a centros nacionales: https://agenda. saluduc.cl/Sinfex/docs/view/f9e5e37b915f434b9f3157ef0b88f559 ointernacionales http://www.mayomedicallaboratories.com/ test-catalog/Overview/48404, http://www.neuroimmunologybcn.org/es/. 
mente progresiva destacan las encefalopatías por priones, cuya presentación clínica puede ser muy similar, pero tienen RM de cerebro característica con hiperintensidad de los caudados/tálamos y/o corteza con restricción en la secuencia de difusión a diferencia de las encefalitis autoinmunes que no restringen, además de LCR no inflamatorio ${ }^{20}$. De los déficits nutricionales debe descartarse, sobre todo, la encefalopatía de Wernicke (puede presentarse sin alteraciones de la oculomotilidad). Las lesiones vasculares (sobre todo infartos talámicos) y las alteraciones metabólicas, si bien son causas muy frecuentes de encefalopatía, su diagnóstico suele ser evidente con el estudio imagenológico y serológico ${ }^{9,25,27,28}$.

También hay que descartar drogas o fármacos principalmente en caso de psicosis confusas o clínica de síndrome neuroléptico maligno ${ }^{11,23,25,27,28}$. Finalmente sobre todo ante una evolución atípica y exámenes complementarios normales, deben considerarse causas primariamente psiquiátricas como un primer brote en esquizofrenia ${ }^{19}$.

\section{Tratamiento}

Una vez que se cumplan los criterios diagnósticos de encefalitis autoinmune posible y se hayan excluido otras causas, se debe iniciar tratamiento inmunosupresor, ya que el retraso en el inicio del tratamiento se asocia a peor pronóstico ${ }^{4,9,15}$. Si bien no existen ensayos clínicos controlados; las dosis, duración de la administración y tiempo de tratamiento son basados en los análisis de series de casos y han sido estandarizados para la encefalitis por AC anti R-NMDA, y se describen en la Tabla $5^{9,29,30}$. El tratamiento de primera línea incluye la extracción de tumor si estuviese presente y corticoesteroides, inmunoglobulinas y/o plasmaféresis. El tratamiento de segunda línea incluye el uso de rituximab, y/o ciclofosfamida $y / u$ otro inmunosupresor en caso que hubiese conflicto con esas alternativas ${ }^{11,23}$.

\section{Descripción de los subtipos de encefalitis autoinmunes más frecuentes:}

\section{Encefalitis por AC anti R-NMDA}

Es la causa más frecuente de encefalitis autoinmune y la que ha sido mejor caracterizada, con seguimiento de hasta 577 pacientes a 2 años promedio $^{11,25}$. Es una entidad predominante en mujeres y en pacientes jóvenes siendo $80 \%$ de los

Tabla 5. Generalidades del tratamiento de la encefalitis autoinmune ${ }^{9,29,30}$

1. Búsqueda activa y resección del tumor compatible con el origen del síndrome

(Ej: teratoma en encefalitis anti R NMDA, cáncer sistémico en encefalitis anti R AMPA)*

2. Posterior a la resección del tumor o si no es hallado, se procede con el primer ciclo de inmunosupresión: 5 días de pulsos metilprednisolona (Metilprednisolona $1 \mathrm{~g}$ al día por 5 días) y de inmunoglobulina intravenosa (lg IV 0,4 g/Kg/día por 5 días) o plasmaféresis

3. Si hay mejoría clara dentro de 10 días, continuar con medidas de soporte

4. Si no hay respuesta o es limitada luego de primer ciclo de inmunosupresión, iniciar un segundo ciclo con: Ciclofosfamida** mensual y Rituximab*** (Semanal por 4 semanas partiendo con la primera dosis de Ciclofosfamida). Dosis de Ciclofosfamida 750 mg/m². Dosis de Rituximab 375 mg/m²

5. Para pacientes con respuesta limitada o sin respuesta a las medidas anteriores, considerar otras formas de inmunosupresión

6. Para pacientes sin tumores, continuar inmunosupresión con Micofenolato o Azatioprina por al menos 1 año después de que el tratamiento primario fue discontinuado (Para evitar el alto índice de recaídas luego de la recuperación)

*Pese a que algunos cirujanos se muestren reticentes a intervenir quirúrgicamente en estos pacientes, la remoción del tumor es crítica en disminuir el tiempo de recuperación y en incrementar las posibilidades de recuperación completa. ${ }^{*}$ Previo al inicio de Ciclofosfamida, se recomienda realizar un test de embarazo en mujeres en edad fértil, hemograma, función renal y hepática. Si se administra de forma intravenosa, controlar con hemograma a los 8-14 días. Se debe estar atento a la aparición de cistitis hemorrágica. Es recomendable involucrar en el manejo utilizando estos fármacos a Reumatólogos y/o Oncólogos que tienen mayor experiencia en su uso ${ }^{9}$. ** Previo al inicio de Rituximab, se recomienda la búsqueda activa de infección por virus de la hepatitis $\mathrm{B}^{30}$ y tuberculosis latente. Posterior al inicio del tratamiento, se requiere monitorización mensual con hemograma ${ }^{9}$. 
casos de sexo femenino y el promedio de edad de 21 años. Hay asociación a tumor en $43 \%$ de las mujeres y $5 \%$ de los varones sobre los 18 años. Dentro de los tumores con mayor asociación a esta entidad se encuentran teratomas ováricos, en menor frecuencia cáncer de pulmón, mama, páncreas, tumores celulares germinales, neuroblastoma y Linfoma de Hodgkin.

La presentación clínica suele tener 3 etapas $^{7,11,25}$; la primera, presente en $70 \%$ de los casos, es un pródromo similar a una virosis respiratoria o gastroenteritis de alrededor de una semana. La segunda son los síntomas neuro-psiquiátricos típicos de encefalitis límbica, pero se agregan conductas estereotipadas y reducción de producción de lenguaje que puede llegar al mutismo y catatonía. Finalmente aparecen movimientos anormales, siendo características las disquinesias faciales, inestabilidad autonómica y una disminución del nivel de conciencia, con hipoventilación. Asociado a esto pueden presentarse crisis convulsivas parciales motoras o parciales complejas, incluso estatus epilépticos ${ }^{11,25}$. La RM de cerebro es en $50 \%$ de los casos normal; las alteraciones son variables desde una típica encefalitis límbica, alteraciones en los ganglios de la base, cerebelo e infrecuentemente la médula espinal, incluso, puede haber solo captación leptomeníngea ${ }^{11,25}$. El electroencefalograma (EEG) es anormal en $90 \%$ de los casos, habitualmente con actividad desorganizada lenta inespecífica, o actividad lenta continua theta- delta en catatonía. En 30\% de los casos puede aparecer una actividad más específica que consiste en un fondo de frecuencia delta generalizada con actividad beta en la superficie, llamado "delta Brush". El LCR es anormal en $80 \%$ de los casos, con pleocitosis linfocítica leve a moderada (aunque hay reportes de hasta 1.000 células), con proteínas normales a levemente aumentadas. Suele haber bandas oligoclonales ${ }^{11,25}$. Debido a lo bien caracterizado de este cuadro se han creado criterios diagnósticos para encefalitis anti R-NMDA probable y definitiva (Tabla 2).

Dentro del seguimiento a 2 años $81 \%$ de los pacientes tuvieron una evolución favorable (definido como mRankin 2 o mejor) y $10 \%$ fallecieron ${ }^{11}$. Como predictores de buen pronóstico se observó el inicio precoz de tratamiento, el no requerir unidad de cuidados intensivos y una severidad baja de la enfermedad a la cuarta semana. Se observaron recaídas clínicas hasta en $12 \%$ de los pacientes, y de ellos, un tercio fueron múltiples. Estas recaídas usualmente fueron menos severas y monosintomáticas y su riesgo disminuye al usar inmunoterapia de largo plazo ${ }^{11}$. Existen 2 series de casos con confirmación de anticuerpos en Latinoamérica, con $11^{31}$ y $13^{32}$ pacientes pediátricos publicados en Argentina y Chile respectivamente. En ambas destaca la ausencia de tumor asociado y una evolución con recuperación total o parcial, siendo lo más frecuente los síntomas conductuales ${ }^{31}$, además se encuentra publicado un caso en Chile de una paciente de 25 años con un teratoma ovárico, que evolucionó con secuelas conductuales ${ }^{33}$.

\section{Encefalitis por AC anti complejo de los canales de potasio voltaje dependiente (VGKC)}

El VGKC tiene distintas subunidades, dentro de las que destacan LGi-1, CASPR2 y Contactina $2^{10,12}$. La por AC anti LGI-1 sería la segunda en frecuencia después de la encefalitis por $\mathrm{AC}$ anti $\mathrm{R}-N M D A$. Este cuadro afecta en general a personas mayores de 50 años y es más frecuente en hombres. De 164 casos de encefalitis autoinmune en China, 6,1\% de los pacientes tenían anticuerpos anti LGi-1 $(+)^{34}$. En una reciente serie de pacientes europeos $^{12}, 66 \%$ de los casos fueron en hombres, con una edad promedio de inicio de 64 años. Se observó tumor subyacente sólo en $11 \%$ de los casos (tumor neuroendocrino de páncreas, timoma, mesotelioma y carcinoma rectal in situ). La presentación clínica es usualmente como encefalitis límbica, alteraciones del sueño tipo trastorno conductual del sueño REM, crisis convulsivas (discognitivas, autonómicas, parciales, gelásticas y tónico clónico generalizadas), crisis faciobraquiales distónicas en la mitad de los pacientes e hiponatremia hasta en 65\% de los casos. La RM puede ser normal, con cambios inespecíficos como atrofia global, o hallazgos de encefalitis límbica. La mayoría de los casos evolucionan a una esclerosis mesial temporal o se normalizan con el seguimiento a 2 años.

Los EEG muestran descargas epileptiformes en $31 \%$ o enlentecimiento focal en $21 \%$. Las crisis faciobraquiales distónicas son muy características de esta entidad, en su mayoría no poseen correlato electroencefalográfico (videos en referencia $35)^{35}$. El LCR de estos pacientes es normal, viéndose leve leucocitosis y/o aumento de proteínas en líquido sólo en $16 \%$ de los pacientes ${ }^{12}$. En la 
evolución a 2 años, $67 \%$ tuvieron un pronóstico favorable (mRankin 2 o mejor) y $19 \%$ fallecieron. Generalmente hay buena respuesta a la inmunoterapia con corticoides con mejoría entre 1 semana a 3 meses, y su inicio precoz podría evitar el deterioro cognitivo ${ }^{35}$. Hay recaídas en $35 \%$ de los pacientes sin inmunoterapia a largo plazo ${ }^{12}$. En Chile hay 1 caso con anticuerpos confirmados publicado en un hombre de 68 años con historia y exámenes compatibles con lo descrito en la literatura ${ }^{36}$.

Encefalomielitis aguda diseminada: Se presenta en general en menores de 40 años, habitualmente postinfeccioso y de curso monofásico. Caracterizado por encefalopatía variable de curso agudo-subagudo asociado a otros signos focales, con neuroimágenes que muestran compromiso multifocal de sustancia blanca supratentorial, ganglios de la base, cerebelo, tronco cerebral y médula espinal de características desmielinizantes e inflamatorias ${ }^{37}$.

Encefalitis de Hashimoto: Es una entidad cuya existencia está en discusión y forma parte del diagnóstico diferencial de encefalopatías respondedoras a corticoides. Se plantean como claves diagnósticas la encefalopatía asociada a crisis convulsivas, mioclonus, alucinaciones y/o episodios stroke-like, enfermedad tiroidea sutil o subclínica, con neuroimágenes normales, o inespecíficas, presencia de anticuerpos antitiroideos (Anti TPO o Antitiroglobulina), y ausencia de otro anticuerpo neuronal ${ }^{38}$.

\section{Conclusiones}

Dado su creciente reconocimiento y prevalencia, las causas autoinmunes siempre deben considerarse en los cuadros de alteraciones de la conducta, cognición o compromiso de conciencia de instalación subaguda, sobre todo en los pacientes jóvenes y una vez descartadas las causas infecciosas, metabólicas y vasculares con un estudio complementario apropiado. Los nuevos criterios diagnósticos de encefalitis autoinmune favorecen el inicio precoz del tratamiento inmunosupresor estandarizado, lo cual se asocia a mejor pronóstico, pero aún está pendiente comprobar su validez diagnóstica.

\section{Referencias}

1. Venkatesan A, Tunkel AR, Bloch KC, Lauring AS, Sejvar J, Bitnun A, et al. Case definitions, diagnostic algorithms, and priorities in encephalitis: Consensus statement of the international encephalitis consortium. Clin Infect Dis 2013; 57 (8): 1114-28.

2. Granerod J, Ambrose HE, Davies NWS, Clewley JP, Walsh AL, Morgan D, et al. Causes of encephalitis and differences in their clinical presentations in England: A multicentre, population-based prospective study. Lancet Infect Dis 2010; 10 (12): 835-44.

3. Armangue T, Leypoldt F, Dalmau J. Auto-immune encephalitis as differential diagnosis of infectious encephalitis. Curr Opin Neurol 2014; 27 (3): 361-8.

4. Graus F, Titulaer MJ, Balu R, Benseler S, Bien CG, Cellucci T, et al. A clinical approach to diagnosis of autoimmune encephalitis. Lancet Neurol 2016; 15 (4): 391-404.

5. Varley J, Taylor J, Associate SRI. Neuropharmacology Autoantibody-mediated diseases of the CNS: Structure, dysfunction and therapy. Neuropharmacology. 2017;

6. Pruss H, Stoecker W. Retrospective analysis of NMDA receptor antibodies in encephalitis of unknown origin. 2010; 1735-9.

7. Dalmau J, Gleichman AJ, Hughes EG, Rossi JE, Peng X, Dessain SK, et al. Anti-NMDA-receptor encephalitic: case series and analysis of the effects of antibodies. 2009; 7 (12): 1091-8.

8. Gable MS, Sheriff H, Dalmau J, Tilley DH, Glaser CA. The frequency of autoimmune N-methyl-D-aspartate receptor encephalitis surpasses that of individual viral etiologies in young individuals enrolled in the california encephalitis project. Clin Infect Dis 2012; 54 (7): 899904.

9. Flanagan EP, Drubach DA, Boeve BF. Chapter 14 - Autoimmune dementia and encephalopathy. In: Pittock SJ, Vincent ABT-H of CN, editors. Autoimmune Neurology. Elsevier; 2016. p. 247-67.

10. Vincent A, Bien CG, Irani SR, Waters P, Wing W, Bethel C. Autoantibodies associated with diseases of the CNS: new developments and future challenges. Lancet Neurol 2011; 10 (8): 759-72.

11. Titulaer MJ, McCracken L, Gabilondo I, Armangué T, Glaser C, Iizuka T, et al. Treatment and prognostic factors for long-term outcome in patients with anti-NMDA receptor encephalitis: An observational cohort study. Lancet Neurol 2013; 12 (2): 157-65.

12. van Sonderen A, Thijs RD, Coenders EC, Jiskoot LC, Sanchez E, de Bruijn MAAM, et al. Anti-LGI1 encephalitis. Neurology 2016; 87 (October 4): 1-8. 
13. Petit-Pedrol M, Armangue T, Peng X, Bataller L, Cellucci T, Davis R, et al. Encephalitis with refractory seizures, status epilepticus, and antibodies to the $\mathrm{GABA}_{\mathrm{A}}$ receptor: a case series, characterisation of the antigen, and analysis of the effects of antibodies. Lancet Neurol 2017; 13 (3): 276-86.

14. Höftberger R, Van Sonderen A, Leypoldt F, Houghton D, Geschwind M, Gelfand J, et al. Encephalitis and AMPA receptor antibodies Novel findings in a case series of 22 patients. Neurology 2015; 84 (24): 2403-12.

15. Lai M, Hughes EG, Peng X, Zhou L, Gleichman AJ, Shu $\mathrm{H}$, et al. AMPA receptor antibodies in limbic encephalitis alter synaptic receptor location. Ann Neurol 2009; 65 (4): 424-34.

16. Hara M, Ariño H, Petit-Pedrol M, Sabater L, Titulaer MJ, Hernandez EM, et al. DPPX antibody-associated encephalitis Main syndrome and antibody effects. Neurology 2017; 88 (14): 1340-8.

17. Titulaer MJ, Soffietti R, Dalmau J, Gilhus NE, Giometto $\mathrm{B}$, Graus F, et al. Screening for tumours in paraneoplastic syndromes: Report of an EFNS Task Force. Eur J Neurol 2011; 18 (1): 19-27.

18. Malter MP, Helmstaedter C, Urbach H, Vincent A, Bien CG. Antibodies to glutamic acid decarboxylase define a form of limbic encephalitis. Ann Neurol 2010; 67 (4): 470-8.

19. Kayser MS, Dalmau J. Anti-NMDA Receptor Encephalitis in Psychiatry. Curr Psychiatry Rev 2011; 7 (3): 18993.

20. Geschwind MD. Rapidly Progressive Dementia. Contin Lifelong Learn Neurol 2016; 22 (2 Dementia): 510-37.

21. Suleiman J, Brilot F, Lang B, Vincent A, Dale RC. Autoimmune epilepsy in children: Case series and proposed guidelines for identification. Epilepsia 2013; 54 (6): 1036-45.

22. González RP, Hudson AL, Basáez ME, Miranda CM. Encefalitis autoinmune por anticuerpos contra el receptor GABA-A: Caso clínico. Rev Med Chile 2016; 144: 1491-3.

23. Dalmau J, Rosenfeld MR. Autoimmune encephalitis update. Neuro Oncol 2014; 16 (6): 771-8.

24. Steiner J. Prevalence of N-Methyl-D-Aspartate Receptor Autoantibodies in the Peripheral Blood: Healthy Control Samples Revisited. JAMA psychiatry 2014; 71 (7): 838-9.

25. Dalmau J, Lancaster E, Martínez-Hernández E, Rosenfeld MR, Balice-Gordon R. Clinical experience and laboratory investigations in patients with anti-NMDAR encephalitis. Lancet Neurol 2011; 10 (1): 63-74.

26. de Boysson H, Boulouis G, Aouba A, Bienvenu B, Guillevin L, Zuber M, et al. Adult primary angiitis of the central nervous system: isolated small-vessel vasculitis represents distinct disease pattern. Rheumatology 2017; 56 (3): 439-44.

27. McKeon A. Autoimmune encephalopathies and dementias. Contin Lifelong Learn Neurol. Dementia 2016; 22(2): 538-58.

28. Jones KC, Benseler SM, Moharir M. Anti-NMDA Receptor Encephalitis. Neuroimaging Clin N Am 2013; 23 (2): 309-20.

29. Rosenfeld MR, Dalmau J. Anti-NMDA-Receptor Encephalitis and Other Synaptic Autoimmune Disorders. Curr Treat Options Neurol 2011; 13 (3): 324-32.

30. Perrillo RP, Gish R, Falck-Ytter YT. American Gastroenterological Association Institute technical review on prevention and treatment of hepatitis b virus reactivation during immunosuppressive drug therapy. Gastroenterology 2015; 148 (1): 221-44.e3.

31. Pérez E, Ruggieri V, Monges S, Loos M, Caraballo R, Rugilo C, et al. Encefalitis aguda mediada por anticuerpos contra el receptor ionotrópico de glutamato activado por N-metil-D-aspartato (NMDAR): análisis de once casos pediátricos en Argentina (Premio Benito Yelín) . Medicina (Buenos Aires) 2013; 73: 1-9.

32. Erazo R, González J, Quintanilla C, Devaud C, Gayoso C, Toledo X, et al. Encefalitis subaguda por anticuerpos anti receptor de N-metil-D-aspartato: Serie de 13 casos pediátricos. Rev Chilena Pediatr 2016; 87: 487-93.

33. Martínez BD, Guerrero TR, Grandjean BM, Cartier RL. Encefalitis autoinmune reversible y anticuerpos anti-receptores de N-metil-D-aspartato. Rev Med Chile 2012; 140 (9): 1170-3.

34. Gao L, Liu A, Zhan S, Wang L, Li L, Guan L, et al. Clinical characterization of autoimmune LGI1 antibody limbic encephalitis. Epilepsy Behav 2016; 56: 165-9.

35. Irani SR, Stagg CJ, Schott JM, Rosenthal CR, Schneider SA, Pettingill P, et al. Faciobrachial dystonic seizures: the influence of immunotherapy on seizure control and prevention of cognitive impairment in a broadening phenotype. Brain 2013; 136 (10): 3151-62.

36. Soler B, Godoy J, Mellado P. Encefalitis límbica por anticuerpos anticanales de potasio dependientes de voltaje: Caso clínico. Rev Med Chile 2009; 137: 675-9.

37. Krupp LB, Tardieu M, Amato MP, Banwell B, Chitnis T, Dale RC, et al. International Pediatric Multiple Sclerosis Study Group criteria for pediatric multiple sclerosis and immune-mediated central nervous system demyelinating disorders: revisions to the 2007 definitions. Mult Scler J 2013; 19 (10): 1261-7.

38. Castillo P, Woodruff B, Caselli R, et al. Steroid-responsive encephalopathy associated with autoimmune thyroiditis. Arch Neurol 2006; 63 (2): 197-202. 